\title{
ETNOGRAFIA DAS PRÁTICAS MUSICAIS NOS AMBIENTES DE TRATAMENTO/CURA/CUIDADO DE UM CENTRO ESPÍRITA: CONCEITOS AFETADOS EM CAMPO
}

\author{
HOZANA REIS PASSOS
}

\begin{abstract}
RESUMO
Trata-se de estudo do campo da Antropologia Musical, em interface com as temáticas de Saúde e Espiritualidade. Proponho dividir com o leitor parte da sistematização dos conceitos sobre ser humano, corpo, saúde, música e espiritualidade que emergiram do campo a partir da investigação sobre os sentidos do fazer musical no contexto de tratamentos espirituais oferecidos pela Sociedade Espírita Everilda Batista, situada no município de Contagem/MG, e suas instituições derivadas. Tais conceitos foram considerados indispensáveis para a investigação dos sentidos produzidos nesse fazer musical em interação com práticas de cuidado desenvolvidas. A prática dos músicos/cuidadores se sobressaiu vigorosamente quanto à formulação dos conceitos apreendidos e dos sentidos do fazer musical da Casa. A música é então considerada um dos elementos terapêuticos no espectro da manipulação de energia, onde o próprio fazer musical pode ser concebido como prática de cuidado em si, sendo esta mediada pelos sujeitos do mundo visível e invisível.
\end{abstract}

\section{PALAVRAS-CHAVE}

Espiritualidade e saúde; música e cuidado; etnografia das práticas musicais; Sociedade Espírita Everilda Batista.

\section{ETNHOGRAPHY OF THE MUSICAL PRACTICES IN THE TREATMENT/HEALING/CARE ENVIRONMENT ATA SPIRITIST CENTER: CONCEPTS AFFECTED IN THE FIELDWORK}

\begin{abstract}
This is a study of the field of Musical Anthropology, in interface with the themes of Health and Spirituality. I propose to share with the reader part of the systematization of the concepts about human being, body, health, music and spirituality that emerged from the field through the investigation of the senses of musical making in the context of spiritual treatments offered by the Spiritist Soc Everilda Batista, located in the city. Contagem / MG, and its derivative institutions. Such concepts were considered indispensable for the investigation of the senses produced in this musical practice in interaction with developed care practices. The practice of musicians / caregivers stood out vigorously regarding the formulation of the concepts learned and the senses of the musical making of the House. Music is then considered one of the therapeutic elements in the spectrum of energy manipulation, where the musical making itself can be conceived as a care practice in itself, being mediated by the subjects of the visible and invisible world.
\end{abstract}

\section{KEYWORDS}

Spirituality and health; music and care; ethnography of musical practices; Spiritist Society Everilda Bastista. 


\section{RÉSUMÉ}

Il s'agit d'une étude dans le domaine de l'Anthropologie Musicale, en interface avec les thématiques de la Santé et de la Spiritualité. Je propose de partager avec le lecteur une partie de la systématisation des concepts sur l'être humain, le corps, la santé, la musique et la spiritualité qui ont émergés lors du terrain, à partir des recherches concernant les sens de la pratique musicale dans le contexte des traitements spirituels proposés par la Sociedade Espírita Everilda Batista, dans la ville de Contagem/MG/Brésil, et ses institutions dérivées. Ces concepts ont été considérés indispensables pour l'étude des sens produits par la pratique musicale en interaction avec les pratiques de soin dispensées. La pratique des musiciens/soigneurs s'est montrée extrêmement expressive par rapport à la formulation des concepts appréhendés et aux significations de la pratique musicale locale. La musique est alors considérée un des éléments thérapeutiques dans le spectre de la manipulation de l'énergie, où la pratique musicale en soi peut être conçue comme pratique de soin, étant mesurée par les sujets du monde visible et invisible.

\section{MÓTS-CLES}

Spiritualité et santé; musique et soins; ethnographie des pratiques musicales; Sociedade Espírita Everilda Batista.

\section{ETNOGRAFÍA DE PRÁCTICAS MUSICALES EN SITIOS DE TRATAMIENTO/CURA/CUIDADO DENTRO DE UN CENTRO ESPIRITISTA: CONCEPTOS AFECTADOS EN EL CAMPO}

\section{RESUMÉN}

Este estudio está embasado en la Antropología musical y abarca los temas de salud yespiritualidad. Planteo compartir con el lector una parte de la sistematización de los conceptos de ser humano, cuerpo, salud, música y espiritualidad que emergieron in loco a partir de la investigación de los sentidos de hacer música en el contexto de los tratamientos espirituales ofrecidos por la Sociedad Espírita Everilda Batista, ubicada en la ciudad. Contagem / MG, y SUS instituciones derivadas. Tales conceptos se consideraron indispensables para la investigación de los sentidos producidos en esta actividad musical en interacción con prácticas desarrolladas de cuidado. La práctica de los músicos / cuidadores se destacó vigorosamente en la formulación de los conceptos aprendidos y en los sentidos de la actividad musical de la Casa. La música se configuró como uno de los elementos terapéuticos dentro de la diversidad de prácticas que abarcan la manipulación de la energía, donde la creación musical puede concebirse propiamente como una práctica de cuidado en sí misma y está mediada por sujetos del mundo visible e invisible.

\section{PALABRAS CLAVE}

Espiritualidad y salud; música y cuidado; etnografía de prácticas musicales; Sociedade Espírita Everilda Batista. 


\section{INTRODUÇÃO}

A partir da vivência da pesquisadora junto às ações de cuidado praticadas em grupos de educação popular em saúde, instituições religiosas e indivíduos que utilizam música no ambiente de tratamento/cura/cuidado, surge a proposta de investigação e reflexão sobre a produção dos sentidos do fazer musical nesses contextos. Assim emerge a pesquisa de mestrado concluída, a partir da adoção da etnografia e etnomusicologia como abordagens metodológicas necessárias para a investigação sobre os saberes e experiências dos sujeitos das práticas musicais e de cuidado coletivo em instituição religiosa, considerada por Valla (2001), espaço de apoio social. Trata-se de um trabalho do campo da Antropologia Musical, em interface com as temáticas de Saúde e Espiritualidade.

Neste artigo, proponho dividir com os leitores parte da sistematização dos conceitos sobre ser humano, corpo, saúde, música e espiritualidade que emergiram do campo a partir da investigação sobre os sentidos do fazer musical no contexto de tratamentos espirituais oferecidos pela Sociedade Espírita Everilda Batista (SEEB), situada no município de Contagem/Minas Gerais, e suas instituições derivadas no município de Sabará/MG. O local para campo de estudo foi escolhido pela diversidade de práticas de cuidado oferecidas, pelo vínculo anterior da pesquisadora com a instituição e pela possibilidade de interação com os sujeitos do fazer musical a ser investigado. Os nomes e instituições citadas nesse estudo são reais e suas identificações foram autorizadas por cada sujeito entrevistado e pelas coordenações da instituição, após serem esclarecidos dos objetivos da pesquisa.

Na Casa de Everilda, nome comumente atribuído pelos sujeitos do campo à instituição, o passe magnético ${ }^{1}$ é realizado em ambientes com canções executadas tanto ao vivo, por músicos, quanto a partir de som mecânico - gravações - no caso da modalidade de tratamento chamada Bioenergia. Existe ainda a Oficina Musical, em que alguns membros se reúnem semanalmente para cantar juntos como forma de tratamento e oportunamente se apresentam durante as reuniões públicas ou palestras. Em ambos os cenários de cuidado, a música ocupa um lugar terapêutico reivindicado pelos membros da instituição, por meio de um discurso musicológico e em saúde marcados.

É oportuno destacar alguns desafios desses encontros etnográficos para a construção investigativa dialógica sobre música, saúde e espiritualidade. O primeiro deles é o exercício descritivo e analítico do conhecimento que emerge do campo, ou seja, a própria escrita etnográfica: assumir a primeira pessoa no texto, estar atenta aos "pequenos grandes detalhes" da vivência no campo, aprender a dialogar com os sujeitos, ouvi-los de fato,

\footnotetext{
${ }^{1}$ Imposição de mãos para transfusão de energia a ser direcionada aos pontos específicos do corpo energético pelo médium, a partir da prescrição do espírito.
} 
Etnografia das práticas musicais nos ambientes de tratamento/cura/cuidado de um centro espírita

esboçar associações entre os gestos, entre os gestos e palavras etc. Apoiei-me em Oscar Saez (2013) quando sugere a postura do etnógrafo como mediador entre culturas e também como mediador entre teorias, além de definir o trabaho de campo como situação de necessária renúncia do controle sobre o objeto de estudo para que se encontre de fato esse objeto construído a partir do campo. O autor também se baseia na etnopsicanálise para afirmar que a subjetividade do pesquisador não é um ruído da pesquisa, mas a própria matéria de seus dados.

Como segundo desafio, estão os deslocamentos epistemológicos provocados pelas aproximações da consciência de "ser afetada" pelo campo, conforme nos sugere FavretSaada (2005) quando nos convida a repensar a antropologia e propõe essa noção como "dimensão central do trabalho de campo", chamando as intensidades específicas, como sensações, percepções e pensamentos, de afetos que devem ser experimentados quando se está no lugar do nativo (lugar esse não imaginável, mas vivido, não em pretensa substituição ou como o nativo), já que a busca por representações e significações, corolários respectivos de um falseamento ou conversão, se tornam insuficientes para uma verdadeira simetria entre saberes. Contudo, a autora ressalta que ao aceitar ser afetado, isso não implica "que o etnógrafo deve identificar-se com o ponto de vista do nativo, nem aproveitar-se da experiência de campo para exercitar seu narcisismo".

O terceiro desafio está no diálogo necessário com a bibliografia espírita psicografada, que foi considerada como uma interlocutora de campo, por sugestão dos cuidadores, trazendo conceitos sobre as temáticas que emergiam durante a pesquisa. Os textos psicografados são de autoria atribuída aos espíritos, seres de um mundo extrafísico, cuja comunicação é feita, segundo escritos espíritas, por pessoas que possuem a capacidade de intermediar tais conteúdos por meio da habilidade mediúnica chamada psicografia (KARDEC, 1862). O objetivo da pesquisa foi investigar a construção de sentidos do fazer musical durante os tratamentos oferecidos pela Sociedade Espírita Everilda Batista, a partir da experiência dos cuidadores/trabalhadores e vivência das pessoas cuidadas/consulentes.

Ao observar essas experiências musicais e buscar na literatura por sistematizações sobre as diversas relações entre pessoas e música, como as contribuições de Lucy Green (1997) e Tia Denora (2004), o termo "sentidos" foi escolhido como uma expressão englobante que melhor se aproxima das significações sobre os saberes e fazeres musicais que se estabelecem enquanto construção social, em ambientes e períodos específicos. Lucy Green (1997) apresenta sistematizações em torno da organização social da prática musical e da construção social de seus significados. Em seu artigo sobre sociologia da educação musical, a autora apresenta a proposta de significados inerentes como aqueles gerados a partir do material sonoro e nomeia de significados delineados a significação em torno do contexto sociocultural de cada indivíduo e do coletivo. Para além da elaboração cognitiva de 
significados pelos sujeitos na relação com a música, a autora Tia Denora (2004) contribui com etnografias onde registra efeitos percebidos e motivações geradas a partir da experiência musical, ampliando então a noção de significação. Dessa forma, a atribuição de sentidos pelos sujeitos das experiências de cuidar e de fazer música tornou-se então uma questão transversal à proposta deste estudo.

A etnomusicologia é aqui considerada como o estudo antropológico sensível à música, que aborda tanto as dimensões estético-estruturais do fenômeno musical quanto os demais aspectos socioculturais que o caracterizam (MERRIAM, 1964; BLACKING, 1973; NETTL, 2004).

O percurso etnográfico foi marcado pela construção, desconstrução e reconstrução do olhar sobre a própria vivência junto às pessoas cuidadas e aos cuidadores, assim como dos conceitos em que os membros da instituição se baseiam para suas práticas. Foram identificadas categorias de análise a partir de relações etnográficas estabelecidas ao longo da prática musical junto aos músicos da Casa, e mediante entrevistas a frequentadores/consulentes, escutas do ambiente e leituras de autores de referência para os nativos sobre música, saúde e a prática espírita ou espiritual, incluindo a visão dos autoresespíritos.

Como lembra Viveiros de Castro (2002, p. 05), a antropologia pode ser definida como "a arte de determinar os problemas postos por cada cultura, não a de achar soluções para os problemas postos pela nossa", o campo tomando forma de "expressão de um mundo possível". O autor nos ensina que o papel do pesquisador é compreender outras possibilidades de mundo. Portanto, quando trabalho com autores-espíritos não estou fazendo nada além de mobilizar as categorias e as 'mundificações' nativas.

Sendo assim, busquei um modo de pesquisar que acolha a multiculturalidade existente nas categorias Música, Saúde e Espiritualidade como integrantes dos modos de ser e viver das pessoas e da instituição em questão. Proponho o exercício do diálogo com essa diversidade, evitando justaposições ou imposições de análises de uma cultura acadêmica de determinado campo sobre outra. Tal postura é referenciada em Freire (1999), quando sugere o conceito de multiculturalidade como fenômeno produzido politicamente e historicamente, que implica a convivência e a necessidade da invenção da unidade nas diferenças.

Em dois anos de trabalho de campo foi realizada uma densa descrição etnográfica em que as vozes dos interlocutores e os fatos ocorridos em campo foram destacados como substrato de pesquisa, para além de pretensões interpretativas ou tradutórias da realidade vivenciada. Contudo, tentarei socializar nesse artigo algumas das sínteses construídas a partir dessas vivências e diálogos, demonstrando alguns conceitos aprendidos com os sujeitos do campo, como por exemplo, as noções de ser humano, corpo, saúde, música e espiritualidade. Tais aprendizados foram considerados indispensáveis para a investigação dos sentidos 
Etnografia das práticas musicais nos ambientes de tratamento/cura/cuidado de um centro espírita

produzidos nesse fazer musical local em interação com as práticas de cuidado desenvolvidas. As categorias que se referem à intencionalidade do fazer musical serão apresentadas de forma breve, pois não se constituem como foco de aprofundamento nesse texto.

\section{APRENDENDO CONCEITOS COM O CAMPO}

Sobre as práticas de cuidado e o conceito de saúde

Рara compreensão das práticas de cuidado no contexto espírita e sua codificação, vale discorrer sobre a significação de ser humano e suas dimensões de existência física e extrafísica, que em resumo se constituem por espírito ou alma, princípio inteligente em que residem pensamento, vontade e senso moral; o corpo, invólucro material que põe o espírito em relação com o mundo exterior; e perispírito, invólucro fluídico, leve, imponderável, servindo de laço e de intermediário entre o espírito e o corpo². Ao observar a prática dos médiuns, fui esclarecida que os mesmos consideram a existência de corpos sutis (GLEBER, 1999), como se fossem "camadas" a serem consideradas para o tratamento do corpo físico, energético, mental e emocional do ser humano.

Existe na instituição, um trabalho sistemático de atendimento às pessoas que comparecem a Casa em busca de tratamento. Semanalmente os voluntários da Casa realizam o acolhimento de quem busca orientação espiritual, que pode ocorrer por meio de psicografia, a partir do fornecimento das iniciais do nome do consulente (pessoa que busca atendimento), ou por conversa com o espírito através do médium. Em seguida, a pessoa é encaminhada aos tratamentos prescritos, que serão realizados ao longo dos meses na própria sede da Casa de Everilda, na Casa Aruanda de Pai João ou na Clínica Holística Joseph Gleber. Essa sistematização promove uma regulação do cuidado, em que as necessidades dos consulentes vão sendo atendidas conforme prioridades identificadas.

Diante das possibilidades terapêuticas encontradas e da organização do processo de trabalho da instituição, reconheço a tentativa de estabelecimento de vínculo com os consulentes a partir do discurso de um cuidado longitudinal e holístico, tendo como expectativa a adesão dos sujeitos às práticas de saúde e de ensino ofertadas, além dos eventos promovidos e livros publicados.

Há uma diversidade de tipos de passe, prática de cuidado situada pelos interlocutores e bibliografia indicada por eles na modalidade de tratamento chamada Magnetismo, que é considerada uma energia não palpável embora ela seja perceptível ao magnetismo e no corpo físico, no sistema nervoso central, nosso tecido mais sutil, que

\footnotetext{
${ }^{2}$ CF. KARDEC, 1860.
} 
também trabalha com a energia que são os impulsos elétricos, segundo Ary Cadeira ${ }^{3}$, coordenador da Clínica Holística Joseph Gleber. Os passes são as práticas de cuidado mais consolidadas no espiritismo, sendo historicamente procurados pelo público em busca de auxílio nos centros espíritas. A transferência magnética é consciente, pois deve ocorrer com o magnetismo do próprio médium, segundo Sônia Diniz (informação verbal) ${ }^{4}$. Sobre as referências para tal trabalho, ela ressalta os autores Jacob Melo, Pasteur e Barão de Potet ${ }^{5}$, além dos livros escritos pelo próprio Robson Pinheiro, como Energia (2008) e Além da Matéria (2003). Além destes, outras modalidades de cuidado são prescritas e oferecidas pelos trabalhadores da Casa. Algumas delas, também possuem a música como mediadora do ambiente terapêutico. São elas: bioenergia/toque terapêutico, apometria, palestras e tratamento médico-espiritual (ectoplasmia).

As modalidades terapêuticas oferecidas pela Casa agregam o cuidado aos corpos citados anteriormente, atuando nas diferentes dimensões de forma conjunta ou separada. Ary Caldeira explica que o tratamento espiritual oferece suporte ao corpo físico para que a pessoa possa estar bem adaptada e com mais energia para passar pelo adoecimento dela, quer seja energético, emocional ou mental. Todas as ações são prescritas pela equipe espiritual com reavaliação ao final do tratamento.

Durante os atendimentos, o consulente é orientado a não interromper o tratamento médico convencional. A ficha de orientação traz uma frase de destaque: "O tratamento espiritual não dispensa o tratamento médico".

Vale ressaltar que alguns conceitos difundidos pelos autores espirituais sobre saúde, e apropriados pelos trabalhadores da Casa de Everilda, não são exclusividade do pensamento espírita. Estes são consonantes em outras práticas integrativas em saúde. Por se identificarem no espectro da filosofia espiritualista e reivindicarem a integralidade no pensamento em saúde, suas teorias estão permeadas por referenciais compartilhados em postulados da física quântica ou da medicina tradicional chinesa, por exemplo. Robson Pinheiro, médium de maior projeção pública da instituição, afirma que foi esclarecido pelas inteligências extrafísicas (espíritos) sobre essa aproximação de conceitos:

"O motivo das 'coincidências' de tais ideias, interpretadas em cada tempo e lugar ao seu modo, em diferentes lugares do planeta e em diferentes épocas, se deve à existência de um conhecimento unificado, integral e universal, que refletem os pensamentos dos seres elevados. Estes são acessados pelas mentes e consciências de

\footnotetext{
3 Ary Caldeira é médico e trabalha como médium na Casa de Everilda Batista. Foi um dos colaboradores estratégicos da pesquisa, concedendo várias entrevistas por mensagens de voz e texto.

${ }^{4}$ Entrevista concedida por Sônia Diniz. [Entrevista II em: 12 set. 2018]. Entrevistadora: Hozana Passos. Contagem, 2018. 01 arquivo mp3 (45 min).

${ }^{5}$ Autores de referência para o cuidado dos corpos invisíveis, segundo a presidente da Casa.
} 
alguns encarnados (cientistas, artistas, pensadores, médiuns) que se sintonizam a essa fonte, por meio de correntes mentais que circundam o planeta, a partir do trânsito de informações, que costumamos chamar de inspiração" (PINHEIRO, 2008, p. 15-21).

Há inclusive profissionais de saúde interessados em tais constructos, haja vista a presença dos mesmos entre voluntários da instituição e em processos de estudo lá mesmo, a partir dessa concepção espiritualista das práticas de saúde.

As falas dos dirigentes e demais trabalhadores da Casa apontam para uma aproximação do conceito de saúde relacionado ao cuidado ao ser humano a partir da integralidade dos sujeitos em seus contextos, acrescentando-se ao já concebido "bem-estar biopsicossocial" da definição da Organização Mundial de Saúde, seus aspectos espirituais, energéticos e emocionais. Vincula-se ainda nesse conceito a necessidade de autoconhecimento, num processo pedagógico de desenvolvimento espiritual.

\section{Sobre concepção e prática religiosa}

A Sociedade Everilda Batista se autodenomina como instituição espírita, que se vincula ao pensamento filosófico de Allan Kardec (2013 [1864]) e apresentam "como projeto pedagógico a educação do espírito"6.

As visão sobre religiosidade e espiritualidade levantada a partir do campo coloca preconceitos do espiritismo eurocêntrico (FERNANDES, 2008) em xeque, a partir do diálogo dos sujeitos com as entidades espirituais atribuídas aos cultos de matriz afrodescendente e brasileira, como os Pretos Velhos e Caboclos da Umbanda. A Casa ultrapassa essas barreiras ao evocar tais entidades em seus espaços de tratamento espiritual sem, contudo, importar os modos culturais advindos de tais crenças ou religiões. Um exemplo é a utilização dos pontos/cantigas de Pretos Velhos que são entoadas nos diversos espaços, porém adaptadas às habilidades musicais dos músicos em sua execução com violão ou mulheres tocando instrumentos de percussão por exemplo. A tensão gerada nessa postura oscila entre a possibilidade aparente de apropriação cultural até a negação dos elementos simbólicos que compõem a religiosidade afro-brasileira. A justificativa das lideranças da instituição se dá pelas seguintes falas: "Não que sejamos umbandistas, mas temos uma ideia mais abrangente de espiritualidade", fala de um dos diretores ao justificar o nome da Casa de Pai João de Aruanda. "Então quer dizer que mentor espiritual quando se apresenta como idoso só pode ser branco e europeu?", fala da Presidente da Casa ao esclarecer sobre a manifestação de espíritos nomeados por ela como pais velhos e mães velhas.

\footnotetext{
${ }^{6}$ Slogan repetido diversas vezes pelos membros da Casa de Everilda.
} 
Ao trazer estas impressões, proponho evidenciar como o campo lida com essa característica de reivindicação de pertencimento a uma religião de origens européias e sua atualização para o contexto brasileiro em seu plano físico ou extrafísico, histórico, político e religioso.

O termo espiritualidade foi também utilizado pelo campo quando os interlocutores se referem ao conjunto de espíritos mentores ou protetores da Casa.

"Música é energia!"

A prática musical durante os tratamentos é justificada pelos interlocutores, dentre outros motivos, pela orientação espiritual para sua utilização, a partir de escritos do espíritoautor Joseph Gleber (2014), que descreve o papel da música como "terapia da alma"; pelos espíritos de Pai João de Aruanda na Reunião dos Pretos Velhos e Caboclos; e pelo Espírito Ariel, sendo este último o coordenador espiritual da Oficina Musical, grupo no qual participei dos encontros semanais por quase um ano, cuja experiência e análises serão abordadas em outro artigo.

Ao adentrarmos a Casa de Everilda cerca de meia hora antes das reuniões públicas, ao subirmos uma rampa no corredor, ouviremos quase sempre alguma canção sendo entoada ao vivo ou por som mecânico no salão.

A canção foi uma forma prevalente de apresentação musical observada. Uma característica do fazer musical que despertou atenção logo nos primeiros registros de campo foi a variedade "estilística" do repertório apresentado ao público. Os gêneros executados, tanto na sala de reuniões quanto na sala de tratamento, variaram entre canções de compositores da chamada música popular brasileira, como Alceu Valença, Roberto Carlos, Rita Lee, Milton Nascimento; composições consideradas hits tocados nas rádios como Trem Bala (Ana Vilela), Dona Cila (Maria Gadú); e canções popularmente atribuídas ao universo católico e protestante, com grande alcance de ouvintes na atualidade ou aquelas consideradas consagradas em tal meio como Sonda-me (Alisson Ambrósio), Amar como Jesus Amou (Padre Zezinho), Anjos de Deus (Eliseu Gomes). Além dessas, ocorrem também algumas execuções de cantigas identificadas como Pontos de Umbanda, que são versos cantados oriundos de uma musicalidade atribuída aos seres do mundo invisível que se apresentam como Pretos Velhos e Caboclos. Outros repertórios que possuem temáticas da religiosidade afro-brasileira são executados pelos integrantes da Casa, como as canções conhecidas pela interpretação dos cantores Dorival Caymmi e Maria Bethânia, por exemplo.

\footnotetext{
${ }^{7}$ Definição realizada pela interlocutora Silvana Santos, uma das trabalhadoras que atua na equipe musical da Casa. Tal definição foi corroborada por seus pares durante a validação das análises em campo.
} 

espírita

A diversidade musical se coloca da mesma maneira que a multiplicidade de temas para palestras, perfis dos palestrantes e variedade estética e artística que se apresenta no palco, como shows de dublagem de Drag Queen em lançamento de livro, esquete de teatro para introduzir tema da reunião pública, apresentações musicais de convidados passando pelo repertório erudito, por canções católicas e evangélicas, grupo de músicas afro-mineiras, corais de outras casas espíritas, duplas de voz e violão etc. Tais características de estética musical podem estar associadas aos modos de ser da instituição, pois suas lideranças estão sempre se afirmando como "formadores de livres pensadores" (fala comum dos dirigentes entrevistados).

Рara Rabelo (2013), o maior desafio ao entendimento das noções/categorias musicais nativas diz respeito à ação musical e compreensão de seus sentidos. Percebemos o fazer musical da instituição como prática de cuidado e não somente como "música ambiente". Daí a necessidade de detalhamento das significações, pois segundo afirma Denora (2004, p.45), "os poderes semióticos da música podem ser 'estabilizados' através das formas em que são constituídos e reforçados através do discurso, através da prática de consumo e através de padrões de uso ao longo do tempo".

Dessa forma, levantamos aqui algumas categorias sobre as principais intencionalidades construídas na relação com o fazer musical, elaboradas e validadas junto aos interlocutores, a partir do resgate de suas narrativas e das reflexões sobre as vivências em campo. É importante destacar que os músicos voluntários da Casa foram referências primordiais para essa síntese e tornaram-se coautores das categorias construídas a partir de nossos diálogos e reflexões sobre suas práticas musicais.

Música e harmonização do ambiente: o termo harmonizar perpassa a narrativa dos músicos como um dos primeiros objetivos de suas performances e pelo que entendi, diz respeito à ação da música sobre o ambiente e também sobre os pensamentos das pessoas:

Lá dentro (sala de tratamento) a energia precisa fluir. O canto de antes de receber os consulentes é para harmonizar a sala. Ai eu toco de tudo. Por exemplo, I Wanna Go Back to Bahia. (Comunicação pessoal, Fabiano Pedrosa, nov. 2017).

A sonoridade é produzida com o sentido de "organizar o ambiente", juntar as vozes no coro, "agregar as pessoas para escutar a música ao invés de conversarem", "limpar os sons do salão", "ajudar na limpeza energética". Por vezes, os integrantes da Oficina Musical se referiam ao "cantar de um jeito harmônico". Ali o sentido estava na afinação das vozes e articulação das palavras no canto coletivo, ao tentarem alcançar a "nota certa" da melodia e realizarem os ataques e finalizações com as vozes no mesmo tempo e em uníssono. Harmonizar passa a ser então, para os músicos, quase um sinônimo de tocar ou cantar. Essa é

\footnotetext{
${ }^{8}$ Optamos por usar o termo "comunicação pessoal" ao invés de "informação verbal" para fontes de entrevistas seguido do nome do entrevistado (devidamente autorizado) e o ano de realização.
} 
uma das palavras mais utilizadas em todo esse período pelos interlocutores. Devido à recorrente utilização de tal expressão, pedi à Sônia, Presidente da Casa, que me ajudasse a defini-la para o contexto da Casa:

Harmonizar é fazer confluir o pensamento, a emoção daqueles indivíduos que são responsáveis pela tarefa para um objetivo comum:

[...] A gente percebe que as pessoas saem de vários lugares, com várias questões de familia, trabalho, cada um com um pensamento num lugar. Então a música faz com que você promova uma convergência de pensamentos. (Comunicação pessoal, Sônia Diniz, 2018).

Dessa forma, harmonizar significa confluir, fazer convergir, provocar sincronia de escutas, pensamentos, posturas e movimentos dos corpos. Portanto, o significado de "harmonizar com a música" no ambiente do salão é passar de um estado em que as pessoas estão dispersas e conversando, para outro em que fiquem atentas ao que será apresentado na reunião. Sônia avalia que dificilmente os coordenadores da reunião conseguiriam promover, sozinhos, tal sincronia para atrair a atenção das pessoas para ouvirem o que será explanado durante uma hora de palestra.

\section{MÚSICA COMO DISPOSITIVO DE ACOLHIMENTO AOS CONSULENTES}

A palavra acolhimento foi utilizada como categoria para explicar o fazer musical desde os primeiros dias do trabalho de campo. Iniciou-se com a minha percepção ao ser atendida na sala, logo depois com Humberto explicando o sentido de sua performance ao violino durante a chegada das pessoas no salão, e concluiu-se com a afirmação de Sônia sobre a necessidade de acolhida da dor com a qual as pessoas chegam:

Então, além do tratar bem quem chega à nossa casa, nós oferecemos a música como o primeiro consolo. Então cada um dentro dessa proposta do acolhimento, de tocar, receber, vai escolhendo as músicas, então há uma preparação pra isso. (Comunicação pessoal, Sônia Diniz, 2018).

Nesse caso, conseguimos identificar duas formas diferentes de acolhimento onde uma música torna-se mediadora. A primeira diz respeito à criação de mecanismos de aproximação da instituição com os frequentadores. E a segunda se refere à intencionalidade de sensibilização desses sujeitos para a recepção das práticas de cuidado.

A segunda forma de acolhimento que identifica a música como mediadora está na intencionalidade de manutenção da atenção do consulente, sensibilizando-o por meio da escuta musical para a recepção da energia magnética que será aplicada. Nessa proposta de acolhida, Fabiano apresenta uma de suas composições para a sala de tratamento explicando que "a pessoa precisa liberar a emoção dela para a luz entrar", dirigindo-se ao próprio 

espírita

consulente na canção:" Se eu estou aqui, acredito em ti/ coro: acredito em ti! Se estás aqui, acredita em mim/ Acredita em mim!/ Sabe que aqui, você vai encontrar.../ Uma mão amiga pra te confortar/ Sinta quanta luz a te iluminar/ Abra o coração e deixe a luz entrar.

O sentido de acolhimento é reconhecido pelas pessoas cuidadas ao avaliarem os possíveis benefícios da música nos tratamentos. Nessa maneira de acolhida, a interpretação das palavras cantadas tem seu destaque. Não há como negar que, nesse caso, as letras das canções são concebidas como mensagens aos consulentes:

A música na sala de tratamento é uma benção... Faz a gente refletir nas letras, até acalmar, porque às vezes a gente entra com o coração partido e aquelas músicas que são tocadas servem de conforto, de consolo [...]. As palavras que são cantadas nas músicas parecem que falam pra gente assim: Ei você não está sozinho, estamos aqui, força, tenha fé, não desista! (Comunicação pessoal, Luciana de Araújo, 2018).

\section{MÚSICA COMO FACILITADORA DO PROCESSO DE TRABALHO DOS MAGNETIZADORES}

Alguns apontamentos dessa categoria já foram descritos nos itens iniciais deste artigo. Contudo, ainda é preciso destacar que o fazer musical é reivindicado pelos magnetizadores como facilitador do processo de trabalho estabelecido. A música aqui, na perspectiva do cuidador, torna-se "combustível" para conservação da energia na sala, "animação" para quem está começando a se cansar, ativa o movimento dos corpos para conseguirem ficar de pé e dá a "sustentação" que precisam para se manterem concentrados na tarefa:

Teve um dia que eu estava com a cabeça lá fora e a música me trouxe para concentrar no que eu estava fazendo, eu estava doando energia. Precisava manter os pensamentos tranquilos. (Comunicação pessoal, Renata Maia, 2018).

Os músicos se tornam cuidadores dos magnetizadores nesse momento, quando observam "o clima da turma" de cada domingo, pois "tem grupo que é mais agitado", "tem gente que fica mais dispersa". Fabiano costuma cantar uma canção, num ritmo que denomina como "rastado", que fez para despertar no grupo a presença de Pai João de Aruanda durante os trabalhos, pois na avaliação dele "é uma música animada, que coloca os magnetizadores pra cima".

\section{MÚSICA COMO ELEMENTO DE SUPORTE AO TRABALHO MEDIÚNICO}

Os médiuns da Casa quase sempre iniciam seus trabalhos com prece, leitura e canto. Essa categoria foi gerada a partir da escuta (à distância) das músicas entoadas na reunião de evocação, onde há o trabalho de psicofonia e abordagem aos espíritos obsessores; da Reunião de Pretos Velhos e Caboclos e também de relatos dos próprios médiuns.

\footnotetext{
${ }^{9}$ Estrofe da canção Luz, composição de Fabiano Pedrosa. Transcrição nossa.
} 
Nesse contexto do trabalho mediúnico, há cantos para momentos específicos, como nos momentos em que o médium encontra-se em estado alterado de consciência, ou seja, no transe mediúnico para possibilitar a comunicação de espíritos. "Às vezes um espírito mais endurecido (obsessor) precisa ser acalmado. Aí a gente usa uma música mais melodiosa, com uma mensagem ou um conteúdo emocional, para tocar a emoção daquele espírito, uma música de Roberto Carlos que fala de amor, por exemplo...", explica Ary. Outrora, são utilizadas canções que o médium denomina "música de virada", "música firme", "com um ritmo mais forte", quando há um "endurecimento energético do espírito ou incompreensão da linguagem que fala mais pela emoção". Ele explica que "são músicas com uma cota de energia suficiente para trabalhar questões como defesa ou represália energética." Para ele, é como se o ritmo também influenciasse nos fluidos do ambiente e fizessem com que este se transformasse com a carga energética maior.

\section{MÚSICA COMO MEIO DE COMUNICAÇÃO COM OUTROS PLANOS}

Nessa perspectiva do campo, a música contribui então para transportar pensamentos e emoções de forma que sejam percebidos por seres do mundo invisível que se identificam com determinadas frequências emanadas durante as respostas das pessoas à escuta ou pelo fazer musical das mesmas.

\section{CONSIDERAÇÕES FINAIS}

Ao resgatar a sistematização dos saberes elaborados a partir dessa experiência etnográfica, fica a constatação sobre a ampliação dos conceitos de ser humano, corpo, saúde, cuidado, espiritualidade e música, apresentadas pelas práticas de cuidado da Casa de Everilda e pelas vozes dos interlocutores de campo, incluindo os autores-espíritos.

Identifico também as possibilidades do fazer musical enquanto prática social que inclui o cuidado entre os sujeitos. As dimensões extrafísicas desse fazer são significadas a partir da consciência de uma relação permanente de trocas energéticas de sonoridades produzidas para o ambiente terapêutico, ao mesmo tempo que o ambiente incide sobre a prática musical de cuidadores músicos, gerando inclusive composições próprias para os espaços de tratamento.

A música é então considerada pela equipe da Casa de Everilda/UNISPIRITUS como um dos elementos terapêuticos no espectro da manipulação de energia, onde o próprio fazer musical pode ser considerado como prática de cuidado de si, sendo esta mediada pelos sujeitos do mundo visível e invisível. Observamos que o saber construído a partir desse cuidado contribui para a aquisição de habilidades musicais específicas e necessárias a esses 

espírita

ambientes culminando numa formação do perfil de músicos cuidadores. Ou seja, não basta "tocar bem" para estar ali, precisa estar atento às demandas do conjunto de trabalhadores e de consulentes e ao ambiente. Além disso, a sala de tratamento, por exemplo, torna-se um espaço de criação musical, criação esta que se torna ferramenta de trabalho de cuidados para os músicos. Tal experiência proporciona a percepção da conjunção música-cuidadoespiritualidade de forma concreta, onde respostas ou efeitos são percebidos pelos consulentes e magnetizadores.

Sobre os cuidadores, percebemos a amplitude das práticas realizadas, com a inclusão do autocuidado, não apenas no discurso. O protagonismo desses trabalhadores nas diversas formas de cuidar e a solidariedade do coletivo desperta o desejo de aprofundar o olhar sobre os processos de trabalho estabelecidos e a abordagem acolhedora ao público que busca os tratamentos.

O conceito de música parece estar próximo da máxima "música é energia", cujo efeito entra e sai das pessoas afetando seus corpos sutis de forma diferente para cada uma delas. Ao mesmo tempo, é atribuída à música a mediação da sincronia de pensamentos, emoções e "estados presenciais" para o cuidado coletivo. Na sala de tratamento, ao "sustentar a energia do ambiente", o cantar dos magnetizadores, por exemplo, apresenta-se como dispositivo de autocuidado, e também como instrumento de performance para acolher aos demais frequentadores.

Um dos desafios metodológicos desse estudo está na construção das categorias aqui sistematizadas, que emergiram de um campo culturalmente heterogêneo, a partir de experiências e diálogos etnográficos articulados com as fontes escritas indicadas pelos interlocutores. Contudo, a prática dos músicos se sobressaiu vigorosamente quanto à formulação dos conceitos apreendidos e dos sentidos do fazer musical da Casa.

Por fim, não poderia deixar de destacar que, ao me permitir ser afetada pelas relações construídas no campo durante a experiência etnográfica, aprendi sobre as diversas dimensões do cuidado propostas pela Casa de Everilda Batista, inclusive sobre autocuidado. Sinto-me também provocada a pensar e transformar os espaços em que ocupo enquanto pesquisadora e trabalhadora de saúde, no que diz respeito à integralidade dos sujeitos e suas potencialidades, construindo a interface entre saúde e espiritualidade a partir das experiências musicais.

\section{REFERÊNCIAS}

BLACKING, John. How musical is man? Seattle e Londres: University of Washington Press, 1973.

DENORA, Tia. Music in everyday life. Cambridge: Cambridge University Press, 2004. 
FERNANDES, Paulo César da Conceição. As origens do Espiritismo no Brasil: razão, cultura e resistência no início de uma experiência (1850-1914). Dissertação (Mestrado em Ciências Sociais) - Universidade de Brasília, Brasília, 2008.

FREIRE, Paulo. Pedagogia da esperança: um reencontro com a pedagogia do oprimido. Editora Paz e Terra, $4^{\mathrm{a}}$ ed. Rio de Janeiro, 1999.

FAVRET-SAADA, Jeane. Ser afetado. Cadernos de Campo, traduzido por Paula Siqueira, n. 13, p. 155$161,2005$.

GLEBER, Joseph (Espírito). A Alma da Medicina. Psicografado por Robson Pinheiro. Contagem, MG: Casa dos Espíritos Editora, 2014.

GLEBER, Joseph (Espírito). Além da matéria: uma ponte entre a ciência e a espiritualidade. Psicografado por Robson Pinheiro.Casa dos Espíritos Editora, $1^{\text {a }}$ ed. Contagem, 2003.

GLEBER, Joseph (Espírito). Medicina da Alma. Psicografado por Robson Pinheiro. Editora Casa dos Espíritos, $6^{\mathrm{a}}$ ed. Contagem, 1999.

GREEN, Lucy. Pesquisa em sociologia da educação musical. Revista da ABEM, Salvador, n. 4, p. 25-35, 1997.

KARDEC, Allan. Livro dos Espíritos. Traduzido por Evandro Noleto Bezerra. 12. ed. Rio de Janeiro: Federação Espírita Brasileira, 2011 [1860].

KARDEC, Allan. 0 livro dos Médiuns ou Guia dos Médiuns e dos Doutrinadores. Tradução da 2. ed. francesa por José Herculano Pires. Cap XXXII: Vocabulário Espírita. 23. ed. São Paulo: Livraria Allan Kardec Editora, 2004 [1862].

KARDEC, Allan. 0 evangelho segundo o espiritismo. Traduzido por Guillon Ribeiro da 3. ed. francesa, revista, corrigida e modificada pelo autor em 1866. 131. ed. Rio de Janeiro: Federação Espírita Brasileira, 2013 [1864].

MERRIAM, Alan P. The anthropology of music. Bloomington: Northwestern University, 1964.

NETTL, Bruno. Excursions in world music. 4. ed. Upper Saddle River, N.J.: Pearson Prentice Hall, 2004.

PINHEIRO, Robson. Os espíritos em minha vida: memórias. Editado por Leonardo Müller. Contagem: Casa dos Espíritos Editora, 2008.

RABELO, Kátia Benati. Daime Música: identidades, transformações e eficácia na música da Doutrina Daime. Dissertação (Mestrado em Música) - Escola de Música, Universidade Federal de Minas Gerais, 2013.

SAEZ, Oscar Calavia. Esse obscuro objeto da pesquisa: um manual de método, técnicas e teses em Antropologia. Ilha de Santa Catarina, Edição do Autor, 2013.

VALLA, Victor. Religião e Cultura Popular: o que a saúde tem a ver com a religião? Rio de Janeiro: DP \& A Editora. Rio de Janeiro, 2001. 
Etnografia das práticas musicais nos ambientes de tratamento/cura/cuidado de um centro espírita

VIVEIROS DE CASTRO, Eduardo. 0 nativo relativo. Mana, n. 8, v. 1, p. 113-148, 2002.

Recebido em 31 de julho de 2019. Aprovado em 26 de novembro de 2019. 